Centre for Global Child Health, Hospital for Sick Children, Toronto, Ontario, Canada

2 Department of Psychology, Kingston University, London, UK

3 Research Program on Children and Adversity, Boston College School of Social Work, Boston, USA

4 Centre of Excellence in Women and Child Health, Aga Khan University, Karachi, Pakistan

Correspondence to: Z A Bhutta zulfiqar.bhutta@sickkids.ca Cite this as: BMJ2020;371:m2876 http://dx.doi.org/10.1136/bmj.m2876 Published: 19 November 2020
TOXIC STRESS AND PTSD IN CHILDREN

\section{Mitigating toxic stress in children affected by conflict and displacement}

\section{Anushka Ataullahjan and colleagues describe the myriad stressors related to conflict and displacement experienced by children and how best to reduce their negative effect}

\author{
Anushka Ataullahjan, ${ }^{1}$ Muthanna Samara, ${ }^{2}$ Theresa S Betancourt, ${ }^{3}$ Zulfiqar A Bhutta ${ }^{1}, 4$
}

Armed conflict and displacement pose a threat to the health and wellbeing of children. As the global community begins to recognize the cumulative effects of conflict and displacement related stressors, our attention has shifted to toxic stress and its short and long term health effects. ${ }^{1}$ Toxic stress, regarded as the result of prolonged activation of the stress response, can occur before birth and during childhood is known to contribute to epigenetic changes, with health and neurodevelopmental consequences. ${ }^{2}$ However, various social factors and early and appropriate intervention can help mitigate the negative effects. ${ }^{3}$

\section{How conflict and displacement affect children}

Over 415 million children were living in conflict affected countries in 2018, ${ }^{4}$ including 33 million displaced children (16 million refugees and asylum seekers, and 17 million internally displaced children). ${ }^{5}$ Although all children are vulnerable to toxic stress, certain subgroups are particularly vulnerable because of their marginalization-for example, orphaned or unaccompanied children, girls, children with HIV infection, and children with developmental disorders or a disability. These groups may face additional stressors and have reduced access to services. The emergence of covid-19 has also raised concerns about spread in conflict affected populations adding to the risk of toxic stress (box 1).

Box 1: Covid-19 in humanitarian settings

Conflict affected populations are particularly vulnerable to covid-19. Overcrowding and inadequate water and sanitation systems in refugee camps and informal settlements, coupled with previously existing illnesses, may increase the spread and severity of covid-19. 67 Moreover, resource and health system constraints may restrict access to adequate and appropriate care. ${ }^{6} 7$ Control measures such as physical distancing may be difficult and may also increase economic precarity, intimate partner violence, and food insecurity in populations already vulnerable because of conflict or displacement.

There are concerns that the health needs of conflict affected populations may be deprioritized by host governments. In refugee camps in Lesbos, Greece, for example, a lack of government support required grassroots mobilization by refugees to increase awareness, create masks, and improve sanitation in their camps. $^{8} 9$ In addition, social isolation and distancing during quarantine are associated with different stressors such as fears, insomnia, anxiety, unfulfilled basic needs, interrupted medical care, and family problems, all of which are common triggers of mental illnesses and suicidal tendencies. ${ }^{10}{ }^{11}$ We must also assume that refugees in host countries will be at greater risk of these problems since they are further socially isolated. Although swift action is needed to control the transmission of covid-19, it is important to ensure that these control measures are context sensitive. ${ }^{7}$

Community based participatory methods can be used to establish youth and community advisory boards to help guide covid-19 mitigation strategies to ensure they are culturally appropriate and thus more effective. ${ }^{7}$ Ensuring that the most vulnerable people are protected may require contextually appropriate measures such as isolation at a household level with designated rooms for vulnerable family members; at street or extended family level, where community members swap houses and designate one home for high risk members; or at neighborhood or sector level, where areas of settlements are designated for only vulnerable individuals. ${ }^{6}$ The Interagency Standing Committee has created guidelines for managing covid-19 that recommend increasing awareness, strengthening health facilities, and strategic planning. ${ }^{12}$

Conflict and displacement increase toxic stress in children through sudden and extreme trauma exposures such as violence and forced displacement (fig 1). Moreover, the frequency and severity of existing daily stressors such as family violence can increase in response to armed conflict. ${ }^{1}$ Data on the number of children affected by conflict who are experiencing toxic stress globally are lacking, but regional studies indicate that it is pervasive. To illustrate, a study from Syria found that $71 \%$ of children experienced frequent bedwetting and involuntary urination, which are common features of toxic stress. ${ }^{13}$ Further research to accurately quantify the extent of toxic exposures faced by conflict affected children is needed. ${ }^{14}$ 


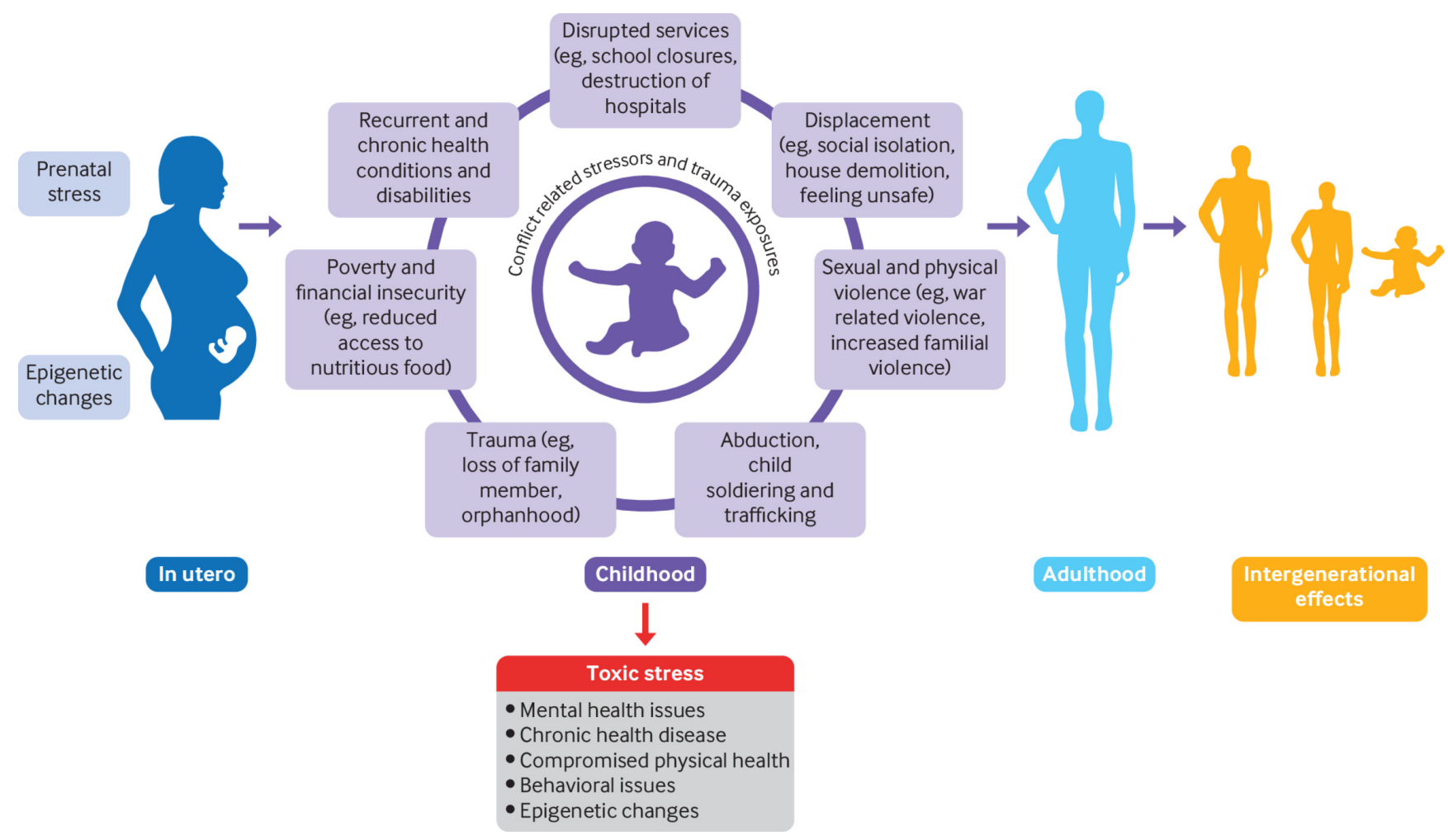

Fig 1 | Conflict related stressors and trauma exposures and their effect through the life course

Active conflict disrupts economic activity and food systems, pushing many families into poverty. ${ }^{15}$ Overhead bombing and artillery fire can damage health, water, and electricity infrastructure, thereby decreasing access to health services, increasing displacement, and physical injury..$^{15}$ The interruption of immunization schedules may cause outbreaks of previously uncommon infectious diseases, as was seen with polio in Syria in 2013. ${ }^{1516}$

Early and repeated exposure to violence can have lifelong effects, including propagating social norms tolerant of violence. ${ }^{17}$ The United Nations Security Council's monitoring and reporting mechanism tracks data on six grave violations against children during armed conflict: killing and maiming, sexual violence, attacks against schools or hospitals, abduction, denial of humanitarian access, and recruitment by armed forces and groups. ${ }^{18}$ All of these grave violations contribute to toxic stress.

Most people affected by conflict are not externally displaced and continue to live in active conflict zones, while some are internally displaced. ${ }^{19}$ For those who are forcibly displaced, the process of displacement can introduce a range of adversities. Raids on homes, schools, and villages as well as political oppression characterize preflight insecurity. Many families remain internally displaced for extended periods, unable to access adequate health, educational, and social services. ${ }^{20}$ During displacement, children may be exposed to increased environmental, social, and physical hazards, including crowded and makeshift living conditions with poor access to water and sanitation. Diseases such as malaria, tuberculosis, and cholera are easily transmitted in these contexts. ${ }^{21}$

Forcibly displaced children and families are often exposed to extreme temperatures and novel disease vectors. ${ }^{22}$ The lost boys of Sudan provide a good example of the physical hardships encountered by unaccompanied minors during displacement. While traveling thousands of miles, many lost their lives to armed militia, wild animals, malnutrition, and exposure to the elements. ${ }^{22}$ Young children, and girls in particular, may be targets of sexual violence as part of systematic militarized action such as the genocidal rape seen in countries from the Balkans to the Great Lakes region in sub-Saharan Africa ${ }^{23}$ or exploitive exchanges by UN peacekeepers, as noted in several countries, including the Central African Republic, and Democratic Republic of Congo. ${ }^{24} 25$

When resettling as refugees in host countries, children may experience stress related to social dislocation, isolation, and adjusting to an unfamiliar language and culture. ${ }^{26}$ Separation from family networks can disrupt children's access to traditional knowledge and protection systems. ${ }^{26}$ Moreover, resettlement policies may further disadvantage asylum seekers by accommodating them in impoverished areas. ${ }^{27}$ Navigating a foreign legal system can be challenging, particularly for orphaned or unaccompanied children. ${ }^{26}$ Disrupted educational systems and lack of economic opportunities may shift marriage practices, with families choosing to marry their daughters young, as has been seen among Syrian refugees in Lebanon. ${ }^{28}$

After resettlement, children may exhibit disruptive behavior, disorientation, and cultural bereavement. ${ }^{26}$ Refugee children report more functional impairment, physical health, psychosomatic, and peer problems. ${ }^{29}$ Parenting can also be challenging as many care givers struggle with their own trauma and emotion dysregulation while learning the norms and practices of a new country. ${ }^{30}$ Adjusting to an unfamiliar and at times unfriendly educational system is an additional challenge for children. Furthermore, the educational progress of some children may be affected by difficulties with concentration and learning. 


\section{Health effects}

Despite a broad understanding of the myriad conflict and displacement related stressors experienced by children, the literature capturing the health effects of these stressors on children is limited. A recent Save the Children report on Syria found that $78 \%$ of children reported feeling extreme grief and sadness at some time. ${ }^{13}$ The report contends that toxic stress coupled with prolonged exposure to war during children's key developmental stages has the potential to become irreversible if appropriate action is not taken quickly. ${ }^{13}$ Evidence from Sierra Leone has shown that lower levels of social stigma and higher community and familial acceptance of former child soldiers was associated with a more positive mental health trajectory and adult life outcomes. ${ }^{31}$

Global evidence suggests that toxic stress continues to affect the health of future generations through epigenetic changes long after conflict has subsided. ${ }^{17}{ }^{32} \mathrm{~A}$ small but growing body of literature has described the intergenerational effects of war, including low birth weight, developmental delays, chronic illness, mental health problems, and intergenerational violence. ${ }^{33}$ Children of parents with post-traumatic stress disorder (PTSD) after the 1994 Tutsi genocide in Rwanda showed higher secondary traumatization symptoms and lower resilience than children whose parents did not have PTSD. ${ }^{34}$ Additionally, new evidence suggests that our knowledge of the interplay between genetics and psychosocial symptoms is still limited. A recent study on male Syrian refugees who participated in a stress attunement intervention found a relation between MAOA genetic variants, which affect the concentrations of the neurotransmitters dopamine, norepinephrine, and serotonin. The MAOA-L variant was associated with sharper reductions of perceived psychosocial stress over time than the MAOA-H variant. ${ }^{35}$

Research with general populations has established the effect of toxic stress on immunological responses. ${ }^{36}$ With infectious diseases such as diarrhea, measles, malaria, and pneumonia and acute malnutrition causing the majority of child deaths in conflict, ${ }^{15}$ the role of toxic stress in increasing susceptibility to these diseases requires further investigation. Research on how toxic stress may influence the development of chronic diseases later in life is also needed.

\section{Mitigating strategies}

\section{Prevention}

Removing the stressor of armed conflict and displacement is arguably the best and most effective strategy to mitigate the impact of toxic stress. Getting the necessary cooperation of a range of state and non-state groups will be difficult, but it is important to recognize the importance of peace and stability for the health of children. These rights are affirmed by the World Health Organization's nurturing care framework, which ensures that children's rights are protected and focuses on their healthy development. ${ }^{37}$

Although halting armed conflict is the ultimate goal, additional safeguards can decrease the effect of conflict on children. The UN's monitoring and reporting mechanism has an important role in monitoring the conduct of state and non-state actors to reduce grave violations against children. ${ }^{18}$ Similarly, funded community monitoring could help to ensure the safety and rights of conflict affected children. Decreasing additional daily stressors by ensuring the basic human rights of families experiencing conflict and displacement through financial assistance, food, housing, education, employment, and healthcare can also benefit children. ${ }^{88}$ As conflict affected settings begin to develop and strengthen health systems, mental health and social services will be critical. ${ }^{39}$
Increasing access to services requires improving refugees' mental health literacy and knowledge of services. $4^{0}$

Improving parenting quality and care giver support can encourage children to build resilience and strengthen protective factors that allow children to better manage stressors. ${ }^{36}$ Positive interactions with primary care givers have an important protective role in reducing synaptic pruning (the process by which extra neurons and synaptic connections are eliminated to increase the efficiency of neuronal transmissions) during childhood. ${ }^{37}$ Furthermore, friendship quality and increased number of friends can protect refugee children from some behavioral and psychological problems. ${ }^{29}$ In contexts of conflict, particularly protracted conflict, we must expect to see intergenerational violence and trauma. By improving care givers' capacity to provide a stable, nurturing relationship and highlighting the role of fathers, the intergenerational effects of war can be mitigated.

\section{Group and community programs}

Since few mental health professionals are available in many war affected settings, various studies have explored the use of group mental health treatments to expand access to care. These models often leverage the strengths inherent in collectivist cultures in war affected regions..$^{41}$ As epidemics or pandemics such as covid-19 further constrain resources and health worker capacity, task shifting to community health workers can allow access to hard-to-reach populations in countries such as Somalia ${ }^{42}$ and Yemen. 43

Community based interventions are important in the short and long term rehabilitation of children experiencing toxic stress. ${ }^{36}$ School based programs can help overcome some of the barriers to access to care and improve educational outcomes. ${ }^{44}$ Awareness of trauma also allows teachers to create a safe and stable environment for students to buffer their stress response. The trauma informed approach focuses on nurturing relations and attachments, increasing ability to self-regulate, and cultivating students' developmental competencies. ${ }^{45}$ Lay counsellors delivering mental health interventions within schools can also improve psychosocial problems. ${ }^{46}$ Furthermore, mentoring schemes and after school clubs have helped refugee children overcome some of their behavioral and psychological difficulties. ${ }^{29}$ Additionally, evidence suggests that social protection services such as cash transfers can benefit child development by reducing the financial stress experienced by families. 47

\section{Family based therapies}

A range of therapies targeting care givers such as carer-child interaction therapy, child and care giver psychotherapy, and stress reduction can help improve stress responses. ${ }^{36}$ Research in Kosovo has highlighted the role of the family in improving children's response to adversity..$^{4} 49$ One study found that mobilizing families to access community based social support services for people with severe mental health illnesses led to increased family coping and quality of life..$^{4}$ Similarly, a study in Rwanda with vulnerable families found that home visits to promote early childhood development improved interactions, reduced violence, and created a more enriched home environment. ${ }^{50}$ The intervention also increased equitable decision making and child dietary diversity. ${ }^{50}$

The success of such interventions shows the interconnectedness of stressors and supports the nurturing care framework approach, which focuses on the links between health, nutrition, safety, care giving, and early education for childhood brain development. ${ }^{37}$ This multisectoral approach integrates health and nutrition 
interventions for children as a way to buffer stress response and decrease the impact of toxic stress. ${ }^{37}$

\section{Personal therapies}

Several approaches aim to build resilience and mitigate the impact of the stress response. Mindfulness based therapies have been shown to decrease psychological distress and anxiety and increase wellbeing. ${ }^{36}$ Biofeedback therapies focusing on decreasing heart and respiratory rates have also been shown to reduce toxic stress, as have other breathing techniques and guided imagery. ${ }^{36}$ These techniques have been used successfully among children and adolescents in Gaza, ${ }^{51}$ Sri Lanka, ${ }^{52}$ and Kosovo. ${ }^{53}$

More traditional approaches such as trauma focused psychotherapy and cognitive behavioral therapy can also ameliorate toxic stress and reduce PTSD symptoms. ${ }^{26}$ Integrating trauma informed treatment across systems of care is essential to ensure that conflict affected and displaced children receive the care they need. ${ }^{54}$ This will require strong collaboration between healthcare providers, development workers, the international community, and governmental and non-governmental organizations. Implementation science can help to develop and test innovative strategies to expand reach and ensure the quality and sustained use of evidence based interventions as conflict affected regions move towards peace and development. 55

\section{Next steps}

Despite the growing evidence on toxic stress in children affected by conflict and displacement, gaps in our knowledge persist. A recent systematic review on the mental health of women, children, and adolescents affected by conflict highlighted the need for interventions to be described in more detail in research papers. 44 Moreover rigorous evaluation of success, failure, and effectiveness of interventions and strategies for widescale implementation in conflict affected regions should be prioritised. ${ }^{44}$ Most research has not included children affected by conflict and displacement, and knowledge of best practices for these contexts is limited (box 2). Existing interventions to reduce toxic stress in regions affected by conflict need to be adapted to take account of cultural context and values, vulnerable subgroups, and resource constraints in their design and delivery.

\section{Box 2: Examples of the rehabilitation of children of conflict}

\section{Bosnia and Herzegovina}

The 1992-95 war had severe long term effects on the health and wellbeing of children and adolescents, with high rates of PTSD, anxiety, and

depression. ${ }^{26} \mathrm{~A}$ Unicef funded psychosocial program, delivered in over 32 secondary schools across the region, shows how appropriate and comprehensive intervention can reduce the rates of reduced

post-traumatic stress, depression, and grief symptoms among children ${ }^{61}$ through normalizing, validating, and processing traumatic experiences. The program also enhanced coping, tolerance, social skills, and problem solving abilities. ${ }^{61}$

\section{Syria}

Syrian refugee children have developed increased mental health problems, including PTSD and emotional dysregulation. ${ }^{62}$ An eight week humanitarian intervention program of structured activities for 12-18 year olds was designed based on the profound stress attunement framework. The intervention reduced symptoms of insecurity, distress and perceived stress, depression, and anxiety and improved behavioral outcomes but had no effect on prosocial behavior or symptoms of PTSD. ${ }^{63}$

\section{Sierra Leone}

Community consultations have been used to adapt common elements of cognitive behavioral therapy and interpersonal therapy to create the youth readiness intervention. The intervention, which focused on increasing emotion regulation, interpersonal skills, and problem solving, was delivered to youth aged $15-24$ years old by trained lay workers. ${ }^{41} \mathrm{~A}$ randomized control trial found that the intervention significantly improved emotion regulation skills, prosocial attitudes and behaviors, and social support, and reduced functional impairment. An eight month follow-up found that participants were more likely to persist in school and had better attendance and academic performance than those who did not receive the intervention. ${ }^{41}$

Appropriate action to reduce toxic stress requires a better understanding of the scope of the problem among children and families affected by conflict. Objective measures of toxic stress are essential, and biomarkers offer one such possibility. A recent study of adolescents affected by conflict showed that hair cortisol concentration can be used to assess response to interventions. ${ }^{56}$ Further research on the use of biomarkers to track and measure stress responses is key to ameliorating toxic stress.

A broader understanding of toxic stress in children is particularly important during the current covid-19 pandemic, when measures to limit the spread of this disease may unintentionally increase exposure to multiple adversities through school closures, movement restrictions, and economic disruption. In India, for instance, where national lockdowns resulted in mass cross-country migrations, children risked separation from family members, economic insecurity, and violence. ${ }^{57}$ The compounding effect of daily stressors and conflict and displacement related stressors encountered by children increases their vulnerability to toxic stress. As social and economic stressors take hold and families are forced into isolation, there has been a rise in family conflict and violence as well as increasing rates of mental health problems among children and their care givers. ${ }^{58}$

Research has indicated that low socioeconomic status, multiple types of violence, and low parental support aggravate the consequences of traumatic events on the development of mental health problems. ${ }^{59}{ }^{60}$ Multisectoral approaches must engage the child, family, community, and, at times, humanitarian groups to prevent and ameliorate the impact of toxic stress among conflict affected and displaced children and strengthen sustainable systems of prevention and care. As the number of people affected by conflict and displacement continues to grow, action to decrease the long term negative effects of toxic stress must be targeted and swift.

\section{Key recommendations}

- Research is needed to determine optimal strategies for sustained implementation of proved interventions to reduce toxic stress

- Clinicians and pediatricians must work closely with other sectors to integrate trauma informed treatment across systems of care

- Response agencies and professionals working with conflict affected and displaced children can mitigate the effects of daily stressors by ensuring access to food, housing, education, employment, financial assistance, and healthcare

- Task shifting and training of lay workers to deliver community based programs can increase access to psychosocial support in marginalized and difficult to reach populations

Contributors and sources: ZAB has over three decades of experience conducting research on the health of women, and children in fragile and humanitarian settings. AA has conducted research in several fragile settings including extensive ethnographic experience in rural Khyber Pakhtunkhwa, Pakistan. MS has expertise on developmental psychopathology investigating mental health in children of war and refugees, particularly focusing on PTSD, and the effectiveness of psychological interventions. TSB has extensive experience researching the longitudinal and intergenerational impact of war experiences on child mental health and development as well as interventions aimed at conflict affected children, families and youth. ZAB conceived the content of this article with AA. All authors contributed to the 
conceptualization of the article. AA wrote the first draft and all authors critically reviewed and approved the final manuscript. ZAB is the guarantor.

Competing interests: We have read and understood BMJ policy on declaration of interests and declare the following: ZAB is the principal investigator of the BRANCH (Bridging Research and Action in Conflict Settings for the Health of women and children) Consortium. AA has contributed to the research activities of the BRANCH Consortium.

\section{Provenance and peer review: Commissioned; externally peer reviewed.}

This article is part of a series commissioned by The BMJ for the World Innovation Summit for Health (WISH) 2020. The BM/peer reviewed, edited, and made the decisions to publish. The series, including open access fees, is funded by WISH.

1 Miller KE, Jordans MJ. Determinants of children's mental health in war-torn settings: Translating research into action. Curr Psychiatry Rep 2016;18:58.

doi: 10.1007/s11920-016-0692-3 pmid: 27091645

2 Nelson CA, Bhutta ZA, Harris NB, Danese A, Samara M. The course of human development can be altered by exposure to adversity in the early years of life. BMJ 2020.

3 McEwen CA, McEwen BS. Social structure, adversity, toxic stress, and intergenerational poverty: An early childhood model. Annu Rev Sociol

2017;43:445-72doi: 10.1146/annurev-soc-060116-053252.

4 Alvhild Strømme ES, Fylkesnes GK, Salarkia K, Edwards J. Stop the war on children: gender matters. Save the Children, 2020.

5 UNICEF. Child migration 2020. https://data.unicef.org/topic/child-migration-and-displacement/migration/.

6 Dahab M, van Zandvoort K, Flasche S, etal. COVID-19 control in low-income settings and displaced populations: what can realistically be done. London School of Hygiene and Tropical Medicine, 2020.

7 Wilkinson A. Local response in health emergencies: key considerations for addressing the COVID-19 pandemic in informal urban settlements. Environ Urban 2020:0956247820922843

8 Lau LS, Samari G, Moresky RT, etal. COVID-19 in humanitarian settings and lessons learned from past epidemics. Nat Med 2020;26:647-8. doi: 10.1038/s41591-020-0851-2 pmid: 32269357

9 Fallon K. The Greek refugees battling to prevent covid-19 with handmade face masks. Guardian 2020 Mar 18. theguardian.com/global-development/2020/mar/18/the-greek-refugees-battlingto-prevent-covid-19-with-handmade-face-masks

10 Brooks SK, Webster RK, Smith LE, etal. The psychological impact of quarantine and how to reduce it: rapid review of the evidence. Lancet 2020;395:912-20. doi: 10.1016/S0140-6736(20)30460-8 pmid: 32112714

11 Yang Y, Li W, Zhang Q, Zhang L, Cheung T, Xiang Y-T. Mental health services for older adults in China during the COVID-19 outbreak. Lancet Psychiatry 2020;7:e19. doi: 10.1016/S2215-0366(20)30079-1 pmid: 32085843

12 Interagency Standing Committee. Interim guidance: scaling-up covid-19 outbreak readiness and response operations in humanitarian situations, including camps and camp-like settings (jointly developed by IFRC, IOM, UNHCR and WHO). 17 Mar 2020. interagencystandingcommittee.org/other/interim-guidance-scaling-covid-19-outbreak-readiness-and-response-operations-camps-andcamp

13 Alun McDonald M, Khush S, Brophy M. Invisible wounds, The impact of six years of war on the mental health of Syria's children.2017. https://resourcecentre.savethechildren.net/library/invisiblewounds-impact-six-years-war-mental-health-syrias-children\#: :text=Research\%20for\%20Invisible\%20Wounds\%20\%E2\%80\%93\%20the,not\%20being\%20able\%20to\%20go

14 Parcesepe A, Stark L, Roberts L, Boothby N. Measuring physical violence and rape against Somali women using the neighborhood method. Violence Against Women 2016;22:798-816. doi: 10.1177/1077801215613852 pmid: 26612274

15 Kadir A, Shenoda S, Goldhagen J, Pitterman SSection on International Child Health. The effects of armed conflict on children. Pediatrics 2018;142:e20182586.

doi: 10.1542/peds.2018-2586 pmid: 30397168

16 Akil L, Ahmad HA. The recent outbreaks and reemergence of poliovirus in war and conflict-affected areas. Int J Infect Dis 2016;49:40-6. doi: 10.1016/j.jijid.2016.05.025 pmid: 27237735

17 Bhutta ZA, Keenan WJ, Bennett S. Children of war: urgent action is needed to save a generation. Lancet 2016;388:1275-6. doi: 10.1016/S0140-6736(16)31577-X pmid: 27613523

18 UN Children and Armed Conflict. The six grave violations. https://childrenandarmedconflict.un.org/six-grave-violations/.

19 Centre for Research on Epidemiology of Disasters. People affected by conflict-humanitarian needs in numbers. 2013. https://reliefweb.int/report/world/people-affected-conflict-humanitarianneeds-numbers-2013

20 UNHCR. Global trends: forced displacement in 2018. 2019. https://www.unhcr.org/globaltrends2018/\#: :text=The\%20global\%20population\%20of\%20forcibly,violence\%2C\%20or\%20human\%20rights\%20violations.

21 Urdal H, Che CP. War and gender inequalities in health: the impact of armed conflict on fertility and maternal mortality. Int Interact 2013;39:489-510doi: 10.1080/03050629.2013.805133.

22 d'Harcourt E, Purdin S. Impact of wars and conflict on maternal and child health. In: Ehiri J, ed. Maternal and Child Health. Springer, 2009: 121-33doi: 10.1007/b106524_7

23 Ruby Reid-Cunningham A. Rape as a weapon of genocide. Genocide Stud Prev 2008;3:279-96doi: 10.3138/gsp.3.3.279
24 Deschamps M, Jallow HB, Sooka Y. Taking action on sexual exploitation and abuse by peacekeepers. Report of an independent review on sexual exploitation and abuse by international peacekeeping forces in the Central African Republic. 2015. reliefweb.int/report/central-africanrepublic/taking-action-sexual-exploitation-and-abuse-peacekeepers-report

25 Notar SA. Peacekeepers as perpetrators: sexual exploitation and abuse of women and children in the Democratic Republic of the Congo. Am Univ J Gender Soc Policy Law 2006;14:413.

26 Lustig SL, Kia-Keating M, Knight WG, etal. Review of child and adolescent refugee mental health. J Am Acad Child Adolesc Psychiatry 2004;43:24-36. doi: 10.1097/00004583-200401000-00012 pmid: 14691358

27 Goldin S, Levin L, Persson LÅ, Hägglof B. Stories of pre-war, war and exile: Bosnian refugee children in Sweden. Med Confl Surviv 2001;17:25-47.

doi: 10.1080/13623690108409553 pmid: 11339342

28 Mourtada R, Schlecht J, Dejong J. A qualitative study exploring child marriage practices among Syrian conflict-affected populations in Lebanon. Confl Health 2017;11(Suppl 1):27. doi: 10.1186/s13031-017-0131-z pmid: 29167699

29 Samara M, El Asam A, Khadaroo A, Hammuda S. Examining the psychological well-being of refugee children and the role of friendship and bullying. Br J Educ Psychol 2020;90:301-29. doi: 10.1111/bjep.12282 pmid: 31056751

30 Betancourt TS, Abdi S, Ito BS, Lilienthal GM, Agalab N, Ellis H. We left one war and came to another: resource loss, acculturative stress, and caregiver-child relationships in Somali refugee families. Cultur Divers Ethnic Minor Psychol 2015;21:114-25. doi: 10.1037/a0037538 pmid: 25090142

31 Betancourt TS, Thomson DL, Brennan RT, Antonaccio CM, Gilman SE, VanderWeele TJ. Stigma and acceptance of Sierra Leone's child soldiers: a prospective longitudinal study of adult mental health and social functioning. J Am Acad Child Adolesc Psychiatry 2019. pmid: 31176749

32 Panter-Brick C, Wiley K, Sancilio A, Dajani R, Hadfield K. C-reactive protein, Epstein-Barr virus, and cortisol trajectories in refugee and non-refugee youth: Links with stress, mental health, and cognitive function during a randomized controlled trial. Brain Behav Immun2019. pmid: 30797045

33 Devakumar D, Birch M, Osrin D, Sondorp E, Wells JC. The intergenerational effects of war on the health of children. BMC Med 2014;12:57. doi: 10.1186/1741-7015-12-57 pmid: 24694212

34 Shrira A, Mollov B, Mudahogora C. Complex PTSD and intergenerational transmission of distress and resilience among Tutsi genocide survivors and their offspring: a preliminary report. Psychiatry Res 2019;271:121-3. doi: 10.1016/j.psychres.2018.11.040 pmid: 30472506

35 Clukay C), Dajani R, Hadfield K, Quinlan J, Panter-Brick C, Mulligan CJ. Association of MAOA genetic variants and resilience with psychosocial stress: a longitudinal study of Syrian refugees. PLoS One 2019;14:e0219385. do: 10.1371/journal.pone.0219385 pmid: 31314763

36 Franke HA. Toxic stress: effects, prevention and treatment. Children (Basel) 2014;1:390-402. doi: 10.3390/children1030390 pmid: 27417486

37 Uchitel J, Alden E, Bhutta ZA, etal. The rights of children for optimal development and nurturing care. Pediatrics 2019;144:e20190487. doi: 10.1542/peds.2019-0487 pmid: 31771960

38 Murray JS. War and conflict: addressing the psychosocial needs of child refugees. J Early Child Teach Educ 2019;40:3-18doi: 10.1080/10901027.2019.1569184

39 Allden K, Jones L, Weissbecker I, etal. Mental health and psychosocial support in crisis and conflict: report of the mental health working group. Prehosp Disaster Med 2009;24(Suppl 2):s217-27. doi: 10.1017/S1049023X00021622 pmid: 19806544

40 Memon A, Taylor K, Mohebati LM, etal. Perceived barriers to accessing mental health services among black and minority ethnic (BME) communities: a qualitative study in Southeast England. BMJ Open 2016;6:e012337. doi: 10.1136/bmjopen-2016-012337 pmid: 27852712

41 Betancourt TS, McBain R, Newnham EA, etal. A behavioral intervention for war-affected youth in Sierra Leone: a randomized controlled trial. J Am Acad Child Adolesc Psychiatry 2014;53:1288-97. doi: 10.1016/j.jaac.2014.09.011 pmid: 25457927

42 Ahmed Z, Ataullahjan A, Gaffey MF, etal. Understanding the factors affecting the humanitarian health and nutrition response for women and children in Somalia since 2000: a case study. Confl Health 2020;14:35. doi: 10.1186/s13031-019-0241-x pmid: 32514300

43 Tappis H, Elaraby S, Elnakib S, etal. Reproductive, maternal, newborn and child health service delivery during conflict in Yemen: a case study. Confl Health 2020;14:30. doi: 10.1186/s13031-020-00269-x pmid: 32514295

44 Kamali M, Munyuzangabo M, Siddiqui FJ, etal. Delivering mental health and psychosocial support interventions to women and children in conflict settings: a systematic review. BMJ Glob Health 2020;5:e002014. doi: 10.1136/bmjgh-2019-002014 pmid: 32201624

45 Tweedie MG, Belanger C, Rezazadeh K, Vogel K. Trauma-informed teaching practice and refugee children: A hopeful reflection on welcoming our new neighbours to Canadian schools. BC Teal Journal. 2017;2:36-45.

46 Michelson D, Malik K, Parikh R, etal. Effectiveness of a brief lay counsellor-delivered, problem-solving intervention for adolescent mental health problems in urban, low-income schools in India: a randomised controlled trial. Lancet Child Adolesc Health2020;S2352-4642(20)30173-5. pmid: 32585185

47 Fernald LC, Hidrobo M. Effect of Ecuador's cash transfer program (Bono de Desarrollo Humano) on child development in infants and toddlers: a randomized effectiveness trial. Soc Sci Med 2011;72:1437-46. doi: 10.1016/j.socscimed.2011.03.005 pmid: 21531060

48 Weine S, Ukshini S, Griffith J, etal. A family approach to severe mental illness in post-war Kosovo. Psychiatry 2005;68:17-27. doi: 10.1521/psyc.68.1.17.64187 pmid: 15899707

49 Weine S, Kulauzovic Y, Klebic A, etal. Evaluating a multiple-family group access intervention for refugees with PTSD. J Marital Fam Ther 2008;34:149-64. doi: 10.1111/j.1752-0606.2008.00061.x pmid: 18412823 
50 Betancourt TS, Jensen SKG, Barnhart DA, etal. Promoting parent-child relationships and preventing violence via home-visiting: a pre-post cluster randomised trial among Rwandan families linked to social protection programmes. BMC Public Health 2020;20:621.

doi: 10.1186/s12889-020-08693-7 pmid: 32375840

51 Staples JK, Abdel Atti JA, Gordon JS. Mind-body skills groups for posttraumatic stress disorder and depression symptoms in Palestinian children and adolescents in Gaza. Int J Stress Manag 2011;18:246doi: 10.1037/a0024015

52 Catani C, Kohiladevy M, Ruf M, Schauer E, Elbert T, Neuner F. Treating children traumatized by war and Tsunami: a comparison between exposure therapy and meditation-relaxation in North-East Sri Lanka. BMC Psychiatry2009;9:22. doi: 10.1186/1471-244X-9-22 pmid: 19439099

53 Gordon JS, Staples JK, Blyta A, Bytyqi M, Wilson AT. Treatment of posttraumatic stress disorder in postwar Kosovar adolescents using mind-body skills groups: a randomized controlled trial. J Clin Psychiatry 2008;69:1469-76. doi: 10.4088/JCP.v69n0915 pmid: 18945398

54 Cohen JA, Scheid J, Gerson R. Transforming trajectories for traumatized children. J Am Acad Child Adolesc Psychiatry 2014;53:9-13. doi: 10.1016/j.jaac.2013.10.004 pmid: 24342380

55 UNISDR. Build back better in recovery, rehabilitation and reconstruction. 2017. https://www.unisdr.org/files/53213_bbb.pdf

56 Dajani R, Hadfield K, van Uum S, Greff M, Panter-Brick C. Hair cortisol concentrations in war-affected adolescents: a prospective intervention trial. Psychoneuroendocrinology 2018;89:138-46. doi: 10.1016/j.psyneuen.2017.12.012 pmid: 29358120

57 India under COVID-19 lockdown. Lancet 2020;395:1315. doi: 10.1016/S0140-6736(20)30938-7 pmid: 32334687

58 Boserup B, McKenney M, Elkbuli A. Alarming trends in US domestic violence during the COVID-19 pandemic. Am J Emerg Med 2020;S0735-6757(20)30307-7. doi: 10.1016/j.ajem.2020.04.077 pmid: 32402499

59 El-Khodary B, Samara M. The relationship between multiple exposures to violence and war trauma, and mental health and behavioural problems among Palestinian children and adolescents. Eur Child Adolesc Psychiatry2020;29:719-31. doi: 10.1007/s00787-019-01376-8 pmid: 31352503

60 El-Khodary B, Samara M. The mediating role of trait emotional intelligence, prosocial behaviour parental support and parental psychological control on the relationship between war trauma, and PTSD and depression. J Res Pers 2019;81:246-56.doi: 10.1016/j.jp.2019.06.004

61 Layne CM, Pynoos RS, Saltzman WR, etal. Trauma/grief-focused group psychotherapy: School-based postwar intervention with traumatized Bosnian adolescents. Group Dyn 2001;5:277doi: 10.1037/1089-2699.5.4.277

62 Khamis V. Posttraumatic stress disorder and emotion dysregulation among Syrian refugee children and adolescents resettled in Lebanon and Jordan. Child Abuse Negl 2019;89:29-39. doi: 10.1016/j.chiabu.2018.12.013 pmid: 30612072

63 Panter-Brick C, Dajani R, Eggerman M, Hermosilla S, Sancilio A, Ager A. Insecurity, distress and mental health: experimental and randomized controlled trials of a psychosocial intervention for youth affected by the Syrian crisis. J Child Psychol Psychiatry 2018;59:523-41. doi: 10.1111/jcpp.12832 pmid: 28967980

This is an Open Access article distributed in accordance with the Creative Commons Attribution Non Commercial (CC BY-NC 4.0) license, which permits others to distribute, remix, adapt, build upon this work non-commercially, and license their derivative works on different terms, provided the original work is properly cited and the use is non-commercial. See: http://creativecommons.org/licenses/bync/4.0/. 